\title{
Letters
}

Website: www.bmj.com

Email: letters@bmj.com

\section{Laparoscopic versus open mesh repair of inguinal hernia}

\section{For most patients hernias provoke} minimal symptoms

EDIToR-In Wellwood et al's trial of laparoscopic hernia repair versus open mesh repair only patients fit for general anaesthesia were preselected. ${ }^{1}$ We do not know if the rejected patients were suitable for local anaesthesia, which is usually ideal for frail and elderly patients and those with high American Society of Anesthesiologists grades.

The type of anaesthesia used greatly affects morbidity associated with elective hernia repair. ${ }^{2}$ As the authors report, after laparoscopic repair with general anaesthesia, patients may have postoperative nausea, vomiting, and retention of urine. Disorientation and cognitive dysfunction may occur with elderly patients after general anaesthesia but are rare after local anaesthesia.

In Wellwood et al's trial postoperative discomfort after laparoscopic repair was reduced slightly, but does it matter? Assessment of postoperative pain is difficult, but elderly patients commonly experience less pain and require less analgesia than young adults after open hernia repair. This might be attributed to the loss of neurones with ageing combined with the decrease in muscle bulk. Although laparoscopic repair is more expensive, many people have suggested that there

\section{Advice to authors}

We prefer to receive all responses electronically, sent either directly to our website or to the editorial office as email or on a disk. Processing your letter will be delayed unless it arrives in an electronic form.

We are now posting all direct submissions to our website within 72 hours of receipt and our intention is to post all other electronic submissions there as well. All responses will be eligible for publication in the paper journal.

Responses should be under 400 words and relate to articles published in the preceding month. They should include $\leqslant 5$ references, in the Vancouver style, including one to the BMJ article to which they relate. We welcome illustrations.

Please supply each author's current appointment and full address, and a phone or fax number or email address for the corresponding author. We ask authors to declare any competing interest.

Letters will be edited and may be shortened.

www.bmj.com

letters@bmj.com are economic benefits of early return to work. In reality this is not so: patients over 60 are unlikely to be engaged in the labour market, so there is minimal benefit. For elderly patients, who represent half of most series, whether laparoscopic repair offers any benefits at all remains to be proved. Even with rapid recovery most employees expect a traditional amount of time off, whereas self employed patients tend to return to work as soon as possible despite any slight discomfort. The ability and desire to return to work are subjective and greatly influenced by personal circumstances.

Laparoscopic repair is a more complex invasive procedure, and catastrophic complications may occur ${ }^{4}$; these are unheard of with open repair. In a statistical sense the non-occurrence of an adverse event in a surgical series, as reported in this trial, does not mean that it cannot happen. Major complications from the pneumoperitoneum, bowel and vascular perforation, and acute and delayed intestinal obstruction do occur.

For most patients a hernia is a benign lump that provokes minimal symptoms. Why expose patients to the major risks of a laparoscopic approach when there are marginal differences in outcome compared with open mesh repair under local anaesthesia, especially when open mesh repair is technically simple, is easily learnt, has consistent results, and is safer and cost effective?

M J Notaras Consultant surgeon London Hernia Centre, London NW6 2QA

1 Wellwood J, Sculpher MJ, Stoker D, Nicholls GJ, Geddes C, Whitehead C, et al. Randomised controlled trial of laparoscopic versus open mesh repair for inguinal hernia: outcome and cost. BMJ 1998;317:1003-10. (11 July.)

2 Teasdale C, McCrum A, Williams NB, Horton RE. Aspects of treatment: a randomised controlled trial to compare local with general anaesthesia for short stay inguina hernia repair. Ann R Coll Surg Engl 1982;64:238.

3 Gardner E. Decrease in human neurones with age. Anat Rec 1940;77:529-36.

4 Fitzgibbons RJ Jr, Camps J, Cornet DA, Nguyen NX, Litke BS, Annibali R, et al. Laparoscopic inguinal herniorrhaphy. Results of a multicenter trial. Ann Surg 1995;221:3-13.

\section{Recurrence rate is true test of hernia} repair

EDIToR-The conclusion that Wellwood et al draw from their randomised controlled tria of laparoscopic versus open mesh repair of inguinal hernia is incomplete. ${ }^{1}$ The authors are to be congratulated on the absence of any major complications from 200 laparoscopic repairs. Would this result be achieved in general surgical procedures, where more severe complications are a feature of most published series? $?^{2-4}$
Surprisingly, their complication rates for the open tension free mesh repair were unacceptably high. In our series of 200 consecutive open repairs reviewed at two years we found a wound infection rate of only $1 \%$ and no cases of testicular atrophy. It is perhaps misleading to include bruising (a minor inconvenience) as though it were as important as severe groin swelling (haematoma?). Similarly, local numbness in a wound after open repair hardly equates with urinary retention after laparoscopic repair.

Figure 3 reports the key results on return to normal activity. Unilateral open repair gives the best results, if only marginally. The prolonged recovery after simultaneous bilateral repair is an argument for sequential repair, which is our policy. Obviously, individual patients express their own preferences.

With differences in recovery being at best marginal, the true test of hernia repair is the recurrence rate. In our series of open repairs there were no recurrences at two years, and in 500 subsequent repairs there have been only three recurrences, all within six months. It is doubtful that the more complex laparoscopic repair can be justified on the data presented. We will be interested to see the results at one and five years.

Keith Rose Surgeon

David Wright Medical director

Charles McCollum Professor of surgery

Surgicare, Manchester M22 4DB

1 Wellwood J, Schulpher M, Stoker D, Nicholls G, Geddes G, Whitehead A, et al. Randomised controlled trial of laparoscopic versus open mesh repair of inguinal hernia: scopic versus open mesh repair of inguinal
outcome and cost. BMJ 1998;317:103-10. (11 July.)

2 Khalili T, Philips E. Complications of laparoscopic hernioplasty. In: Maddern G, Hiatt J, Phillips E, eds. Hernia repair. plasty. In: Maddern G, Hiatt J, Phillips E, eds.
London: Churchill Livingstone, 1997:177-81

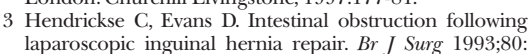
1432.

4 Davies NM, Dunn DC. Experience with 300 laparoscopic inguinal hernia repairs with up to 3 years follow-up. Ann $R$ Coll Surg Engl 1995;77:409-12.

\section{Laparoscopic repair is good when} undertaken by experienced surgeons EDITOR-Wellwood et al's report of their trial of laparoscopic versus open mesh repair of inguinal hernia is important as much for what is not said as for what is.

This was a selective randomised study: patients deemed unfit for general anaesthesia were excluded. The number in this group is not given and would include those with serious cardiac or pulmonary disease, the very group most suitable for local anaesthesia. This study thus compares two operations performed on a select group of relatively healthy patients, which produces a bias in favour of laparoscopic repair. 
The inclusion of recurrent hernias (roughly $10 \%$ in each group) is not helpful. Recurrent hernias are a separate entity, with differing anatomy, sites, and complications. Recurrences after laparoscopic repair require open repair, and open repair often requires preperitoneal abdominal repair.

The short term benefit of laparoscopic repair in terms of postoperative pain is well recognised. However, a fifth of our patients having tension free mesh repairs experienced almost no pain and needed no postoperative analgesia. ${ }^{2}$ Furthermore, the study does not distinguish between younger and older groups, older patients having considerably less pain.

The time of return to work shows sedentary workers resuming in 10 days and active workers in 17 days. This is at variance with our experience of 3175 open repairs, ${ }^{3}$ in which the median time of return to work for office workers was 7 days and for active workers 14 days (this further reduced to 8 days in the past two years).

The rate of sepsis in the open group was $11 \%$; the authors do not distinguish between minor superficial and more important deep sepsis. They do not comment on the effect of prophylactic antibiotics in the $41 \%$ of open repairs. The authors make considerable omissions in their estimates of cost. Additional staff are required when general anaesthesia is used, which adds substantially to the cost of laparoscopic repair.

In conclusion, this trial confirms that laparoscopic repair of groin hernia is a good operation when undertaken by experienced laparoscopists in healthy patients, but the incidence of serious visceral or vascular injury, widely reported, cannot be overlooked in less experienced hands.

\section{A E Kark Surgeon}

M N Kurzer Surgeon

P A Belsham Surgeon

British Hernia Centre, Hendon, London NW4 4RS

1 Wellwood J, Sculpher MJ, Stoker D, Nicholls GJ, Geddes C, Whitehead A, et al. Randomised controlled trial of laparoWhic versus open mesh repar for inguinat heroscopic versus open mesh repair for inguinal

2 Kark AK, Kurzer MN, Waters KT. Tension-free mesh Kark AK, Kurzer MN, Waters KT. Tension-free mesh
hernia repair: review of 1098 cases using local anaesthesia in a day unit. Ann R Coll Surg Engl 1995;77:299-304.

3 Kark AK, Kurzer MN, Belsham PA. Three thousand one Kark AK, Kurzer MN, Belsham PA. Three thousand one
hundred seventy-five primary inguinal hernia repairs: hundred seventy-five primary inguinal hernia repairs:
advantages of ambulatory open mesh repair using local

anaesthesia.J Am Coll Surg 1998;186:447-55.

\section{Laparoscopic repair can be made less} expensive

EDIToR-The paper by Wellwood et al confirms the opinion of most open minded surgeons with experience of both laparoscopic and open hernia repair. ${ }^{1}$ The results are similar to those of our ongoing trial at $\mathrm{St}$ George's Hospital comparing an entirely extraperitoneal approach with an open mesh repair. We believe that the extraperitoneal approach is superior to the transperitoneal one, although the learning curve is considerably longer.

We question the need to use disposable equipment, which resulted in the laparoscopic repair being more expensive than the open repair. The well documented risks of stapling can be readily avoided by using sutures. If fixation of the patch is thought to be necessary this requires only one or at most two sutures for accurate placement, and the peritoneal incision can be sutured easily in the same time that it takes to staple and at minimal cost. This also eliminates the requirement for a $12 \mathrm{~mm}$ port. Likewise, the use of fully disposable scissors is unnecessary. Elimination of these additional costs makes the cost of the two procedures similar; if the ability of patients having laparoscopic repair to return earlier to all normal activities is also taken into account, laparoscopic repair becomes the least expensive procedure.

R S Taylor Consultant vascular and general surgeon A Naseef Registrar

E Brandt Research nurse

$\mathbf{S}$ Jacob Senior registrar

St George's Hospital, London SW17 0QT

1 Wellwood J, Sculpher MJ, Stoker D, Nicholls GJ, Geddes C, Whitehead A, et al. Randomised controlled trial of laparoscopic versus open mesh repair for inguinal hernia outcome and cost. BMJ 1998;317:103-10. (11 July.)

\section{Unblinded trials may not be more} reliable than observational studies

EDITOR-Wellwood et al's study highlights difficulties in undertaking randomised trials in surgery. Two consultants and five trainees performed the operations. The operating skills of the two groups may have differed. Trainees performed fewer procedures and were slower at laparoscopic operations; this may reflect their expertise, ease with the procedure, or previous volume of cases performed. Supervising trainees in five laparoscopic procedures before they undertake trial operations may not be sufficient to ensure a standardised approach by al operators. It would have been interesting to know how many laparoscopic procedures each trainee actually performed.

The duration of bilateral open repair operations was not, as might be expected, twice that of unilateral open repairs but 1.4 times. Interoperator variability in surgical technique may mean that patients did not receive the same standard intervention. The authors did not state if the operator was designated before or after randomisation. It might have been more appropriate to restrict operators to experienced consultants.

Inability to blind surgeons, patients, and assessors is also a problem in many surgical trials. Blinding is a key feature of clinical trials $^{2}$; without it, clinical enthusiasm (or scepticism) may bias interventions and assessment-a possibility in this study as most outcome measures were based on decisions or subjective assessments by doctors, a nurse or patients. Partial blinding in another laparoscopic trial (of cholecystectomy ${ }^{3}$ ) failed to show expected early differences, which suggests that postoperative management and patients' perception are influenced by knowledge of the procedure.

Another difficulty in surgical trials is defining an appropriate end point. Although the sample size was based on use of analgesics and return to normal activity, over 50 statistical comparisons were made between the groups, which makes it difficult for readers to make their own conclusions.
The longer term results will be more helpful, as short term benefits become relevant only if laparoscopic surgery does achieve low recurrence rates. ${ }^{4}$ The authors comment on cost effectiveness without presenting actual cost effectiveness data. Judgments on cost effectiveness cannot be made as their costs were not linked to any outcome; this is a necessary step in cost effectiveness analysis and probably reflects difficulty in defining an appropriate outcome.

Unblinded surgical trials are fraught with bias, particularly if they use subjective outcomes assessed by the doctor or patient. We accept the need for more clinical trials in surgery, ${ }^{5}$ but unblinded trials may not eliminate bias encountered when nonrandomised controls are used and will not necessarily provide more reliable data than well conducted observational studies.

Ani Anyanwu Research fellow

Surgical Epidemiology and Audit Unit, Royal College of Surgeons of England, London WC2A 3PN

aanyanwu@rcseng.ac.uk

Dermot O'Riordan Specialist registrar in general

surgery

Princess Alexandra Hospital, Harlow CM20 1QX

1 Wellwood J, Schulpher M, Stoker D, Nicholls G, Geddes G, Whitehead A, et al. Randomised controlled trial of laparoscopic versus open mesh repair of inguinal hernia: outcome and cost. BMJ 1998;317:103-10. (11 July.)

2 Bradford Hill A. The clinical trial. Br Med Bull 1951;7: 278-82

3 Majeed AW, Troy G, Nicholl JP, Smythe A, Reed MW,

Stoddard CJ, et al. Randomised, prospective, single-blind Stoddard CJ, et al. Randomised, prospective, single-blind
comparison of laparoscopic versus small-incision cholecomparison of laparoscopic versus

4 Rutkow IM. The recurrence rate in hernia surgery: how important is it? Arch Surg 1995;130:575-6.

5 Horton R. Surgical research or comic opera: questions, but few answers. Lancet 1996;347:984-5.

\section{Costs and outcomes should always be presented in disaggregated form}

EDitor-Wellwood et al's study relates the outcomes of two types of repair for inguinal hernia to the resources that were used. ${ }^{1}$ The authors omitted a crucial part of the overall picture and in doing so showed an important point that should be considered when economic analyses are undertaken.

Although from a societal perspective the costing of wage and non-wage time remains controversial to the patient and hence the general practitioner, this element is important. In many cases in this study these costs will probably be greater than the stated NHS costs as one of the greatest differences between the two procedures is likely to be the time taken to return to work. Unfortunately, this simple outcome is not recorded and the adoption of a narrow NHS viewpoint precludes the calculation of both societal and individual perspectives.

Costs and outcomes should always be presented in disaggregated form so that all stakeholders can analyse the data from their individual perspectives.

D P Kernick Lead research general practitioner Deborah Reinhold Research coordinator St Thomas Medical Research Unit, Exeter EX4 1HJ

1 Wellwood J, Schulpher M, Stoker D, Nicholls G, Geddes G, Whitehead A, et al. Randomised controlled trial of laparoscopic versus open mesh repair of inguinal hernia outcome and cost. BMJ 1998;317:103-10. (11 July.) 


\section{Laparoscopic repair is much more} expensive

EDITOR-The results of Wellwood et al's prospective randomised trial of laparoscopic versus open mesh repair for inguinal hernia ${ }^{1}$ depend on one's emphasis. The authors conclude that "laparoscopic hernia repair has considerable short term clinical advantages after discharge, although it was more expensive." It could also be stated that laparoscopic hernia repair has some short term clinical advantage but is considerably more expensive. An extra $£ 335$ per operation would add many millions to the NHS bill, and even if this sum was reduced to $£ 100$ per operation it would still have considerable financial implications because the operation is so common.

Perhaps patients could be offered the mesh repair free but be asked to pay a supplement if they would like it done laparoscopically.

A G Johnson Professor of surgery

Department of Surgical and Anaesthetic Sciences, Royal Hallamshire Hospital, Sheffield S10 2JF

1 Wellwood J, Schulpher M, Stoker D, Nicholls G, Geddes G, Whitehead A, et al. Randomised controlled trial of laparoscopic versus open mesh repair of inguinal hernia outcome and cost. BMJ 1998;317:103-10. (11 July.)

\section{Identification of patients with atrial fibrillation in general practice}

\section{Large sample sizes would be needed for opportunistic screening for atrial fibrillation}

EDITOR-Sudlow et al suggest that detecting and treating atrial fibrillation in people aged over 65 could greatly reduce the incidence of stroke. ${ }^{1}$ They also suggest searching for prescriptions for digoxin and opportunist pulse palpation as practical approaches to identifying patients with atrial fibrillation.

The Cumbria Practice Research Group investigated these methods in patients over 60 to assess: the prevalence of atrial fibrillation in the population; the number of patients eligible for warfarin treatment; the number of those eligible for warfarin treatment who would agree to start it; adverse events caused by warfarin; the practical aspects of initiating warfarin treatment in the community; and the sample size needed for a study measuring the outcome of treatment with warfarin after screening for atrial fibrillation.

We flagged patients' records with a Post-it note asking the next person who saw the patient to check whether the pulse was irregular. We offered patients with an irregular pulse an assessment including electrocardiography to identify atrial fibrillation and completion of a checklist for eligibility for warfarin treatment. If eligible they were then offered treatment. Those who declined or were ineligible were offered aspirin unless it was contraindicated. During 12 months $85 \%$ of the target population were screened.

In one practice (list size 4760) 33 patients were taking digoxin. Twenty three were considered ineligible for warfarin by the general practitioner for reasons including dementia, other serious illness, and lack of transport to attend for blood tests. Ten were invited for full assessment, of whom nine attended. Of these, four were considered eligible for warfarin and two agreed to treatment. Another 32 patients were identified with an irregular pulse during opportunistic screening. Ten were not in atrial fibrillation on further assessment. Eleven were considered to be ineligible for warfarin by the general practitioner for reasons including undiagnosed haematuria and previous gastrointestinal bleeding. Three patients declined the assessment. Of the eight assessed, two were eligible for warfarin, of whom one accepted and one declined.

Our study showed that it is feasible to screen for atrial fibrillation opportunistically and by use of digoxin prescriptions. Fewer patients than we expected, however, were eligible for and actually agreed to start treatment with warfarin. Sudlow et al comment that controlled trials of the effect of screening on clinical outcomes are needed. Our study suggests that the sample size needed for such a trial will be far greater than originally expected.

Eleri Roderick General practitioner

Jim Cox General practitioner

Caldbeck, Wigton, Cumbria CA7 8DS

Eleri.Roderick@BTInternet.com

1 Sudlow M, Rodgers H, Kenny RA, Thomson R. Identification of patients with atrial fibrillation in general practice: tion of patients with atrial fibrillation in general practice: a
study of screening methods. BMJ 1998:317:327-8. (1 August.)

\section{"While we're there" research disguises need for screening studies}

EDITOR-Sudlow et al's article on identifying patients with atrial fibrillation in general practice highlights the problems of "while we're there" research. ${ }^{1}$ The original study set out to identify the community prevalence of atrial fibrillation, yet this report tries to identify the reliability of pulse taking and note searching as a means of identifying patients with this condition. Screening for atria fibrillation is beset with the problems of lack of data regarding community prevalence and uncertainty over the true treatment effect of warfarin, given the highly selected populations in the primary trials.

It is unhelpful to suggest that the specificity of pulse taking is between $71 \%$ and $86 \%$ against a gold standard of limb lead electrocardiography interpreted by an unknown source. This study suggests that an advance has been made in terms of our understanding of how best to detect atrial fibrillation. But it disguises the fact that a full blown screening study is needed to evaluate al potential screening methodologies, including systematic versus opportunistic screening, and that this should be done in combination with an intervention study to evaluate the real treatment effect of antiplatelet versus anticoagulant treatment before any conclusions can be drawn. Until all the data required to evaluate both sides of this equation (screening and treatment) are available we will continue to be guessing as to the benefit or harm we are doing to our patients on both an organisational and an individual level.

This kind of add on research limits the potential for answering the real questions and adds nothing to the evidence base we need to answer everyday clinical problems.

D A Fitzmaurice Senior lecturer

University of Birmingham, Birmingham B15 2T D.A.Fitzmaurice@bham.ac.uk

1 Sudlow M, Rodgers H, Kenny RA, Thomson R. Identification of patients with atrial fibrillation in general practice: study of screening methods. BMJ 1998;317:327-8. (1 August.)

\section{A national target for reducing suicide}

Suicide in older people must be reduced

Editor-Hawton's editorial emphasises the importance of continuing to set national targets to reduce the rate of suicide. ${ }^{1}$ We were surprised, however, by the groups that were selected as being particularly at risk of suicide and therefore as requiring special attention.

We agree that the rise in the rate of suicide in young men, both nationally and internationally, is of considerable concern. Suicide rates in men over 75 are still, however, the highest in any demographic group. Although it is difficult to predict future changes in rates of suicide accurately, evidence from birth cohort analyses suggest that rates of suicide in older people will increase. ${ }^{2}$ Targeted approaches for reducing suicide in older people would include optimising the management of pain and disability and reducing handicap and social isolation.

Among people who deliberately harm themselves, older people are even more likely than younger people to die by suicide. ${ }^{3}$ Casualty and primary care staff should therefore be particularly alert to older people in this category. Self poisoning is the most commonly used method of suicide in older people. Limiting the availability of analgesics and other drugs in those known to be at risk of self harm is therefore a central concern.

Finally, we agree with Hawton that the Samaritans should continue to receive support. For the first time, contacts with people aged over 60 now make up $8 \%$ of calls to the Samaritans-that is, one new call every 15 minutes in the United Kingdom. ${ }^{4}$ In Singapore, the Samaritans offer a toll free telephone line for distressed elderly people, and the effectiveness of this service, although difficult to show, is being monitored.

\section{Abas Lecturer}

M J Crawford Research fellow

Section of Old Age Psychiatry, Institute of Psychiatry, London SE5 8AF spjumaa@iop.bpmf.ac.uk

1 Hawton K. A national target for reducing suicide. $B M$ 1998;317:156-7.(18 July.)

2 Shah A, De T. Suicide and the elderly. Int J Psychiatry Clin Pract 1998;2:3-17.

3 Cattell H, Jolley DJ. 100 cases of suicide in elderly people. BrJ Psychiatry 1995;166:451-7.

4 Abas MA. Depression and suicide in older people. Int J Geriatr Psychiatry 1995;10:707-10.

5 Ko SM, Kua EH. Ethnicity and elderly suicide in Singapore. Int Psychogeriatrics 1995;7:309-17. 
People over 65 should be a target group EDITOR-In addition to the three target groups that Hawton proposes in his editorial on setting a national target for reducing suicide, ${ }^{1}$ attention should be directed at older adults presenting with deliberate self harm. Consensus guidelines produced by the Royal College of Psychiatrists make brief but clear reference to older adults: "It should be usual to refer patients aged over 65 years to the specialist service as a matter of routine."' Macdonald has gone further, stating that psychiatric admission is necessary for "any serious suicide attempt or trivial suicide attempt or self harm for the first time in old age." ${ }^{3}$ This view has considerable merit but has not been widely accepted.

The assessment of risk of suicide should be both systematic and routine. Various factors statistically associated with completed suicide have been identified by a number of authors and checklists proposed. ${ }^{4}$ Limitations in terms of specificity and sensitivity, however, mean that "scales of this kind can at best be no more than a useful adjunct to routine clinical assessment." ${ }^{\prime 5}$ A tactful but thorough face to face interview is essential

Even a cursory examination will show that almost all older patients presenting with deliberate self harm have several clinically important risk factors for completed suicide and are depressed. These patients should therefore always be viewed as being at high risk. It is equally important that mental health services identify these patients as a priority and ensure that adequate time is given to identifying all the relevant factors in order to reduce or modify the risk of suicide. One practical solution is to offer a psychiatric admission for assessment routinely.

Benchmark figures for deliberate self harm in older adults in the population served by Bridgend and District NHS Trust have been obtained from local clinical audit data over 18 months. Altogether 1.5 incidents per 1000 population aged over 65 occur annually, which for the trust's current population of around 24000 aged over 65 amounts to 36 episodes a year.

Older adults presenting with deliberate self harm deserve to be identified, thoroughly assessed (as psychiatric inpatients), and professionally managed by a mental health service. If this is achieved then the government's target of a further reduction in the national rate of suicide will come within reach.

Robert Colgate Consultant in old age psychiatry Glanrhyd Hospital, Bridgend CF31 4LN

1 Hawton K. A national target for reducing suicide. $B M$ J 1998;317:156-7. (18 July.)

2 Royal College of Psychiatrists. The general hospital manage ment of adult deliberate self-harm. London: RCP, 1994:10.

3 Macdonald AJD. Mental health in old age. BMJ 1997 315:413-7

4 Williams R, Morgan HG. Suicide prevention-the challenge confronted. London: NHS Health Advisory Service, 1994.

5 Morgan HG Assessment of risk In: Jenkins R, Griffiths S, Wylie I, Horton K, Morgan G, Tylee A, eds. The prevention of Wylie I, Horton K, Morgan G, Tyl
suicide. London: HMSO, 1994:49.

\section{Unexplained haemoglobinuria may have been haematuria}

EDITOR-McConkey (and Medline) wonders about the cause of haemoglobinuria on three occasions during stress in a fit young officer who without any treatment was still doing well 48 years later. ${ }^{1}$ Malingering is ruled out by the circumstances.

A likely explanation is that the "haemoglobinuria" was actually haematuria caused by a haemangioma in the urinary tract. The bleeding was due to the raised blood pressure associated with stress. Swan and Balme reviewed the literature on 27 patients with bleeding renal haemangiomas who had a median age of 30 years with a range of $<10$ to $>70$ years. $^{2}$ Twenty six were diagnosed after nephrectomy was performed because of suspected malignancy, which in McConkey's case is fortunately ruled out by the survival of his patient.

Imaging of the upper urinary tract and a cystoscopy should be done in any patient with unexplained haematuria to rule out neoplasia, silent stones, etc. Officers of any responsible airline system are grounded in case of unexplained haematuria for safety reasons. I believe that this should apply for military officers as well.

Svend Mortensen Chief urologist

Amtssygehuset, 2600 Glostrup, Denmark

1 McConkey B. Ceremonial haemoglobinuria. BMJ 1998 317:153. (11 July.)

2 Swan RHJ, Balme H. Angioma of the kidney: report of a case and review of 26 previously reported cases. BrJ Surg 1935;23:282-95.

\section{Simvastatin seems unlikely to cause impotence}

EDITOR-Last year Jackson reported on five men who developed impotence with profound lethargy and inertia after starting treatment with or increasing the dose of simvastatin. This resolved after treatment was discontinued. ${ }^{1}$ The author also cited reports of impotence with this drug from Australia.

Impotence is not uncommon in middle aged and elderly men, the group most commonly prescribed lipid lowering drugs. The frequency and nature of the disorder introduce potential bias into investigations such as those conducted by Jackson-namely, stopping the drug and watching or rechallenging with the drug (in two cases) without control patients. The message given to patients when a statin is prescribed is important for how they tolerate the drug in the future. If patients get the impression that their future health and survival will depend on taking a drug that interferes with some fundamental parts of their body systems for the rest of their lives, some will react with temporary lethargy and impotence. Patients will be eager to blame external factors and will be relieved if their doctor suggests a reason for the problem. Only placebo controlled randomised clinical trials can answer the question of whether there is really a connection between impotence and treatment with simvastatin. In the Scandinavian simvastatin survival study, 4444 patients with coronary heart disease were randomised to treatment with simvastatin or placebo for up to 6.2 years. ${ }^{2}$ The table gives the numbers spontaneously reporting temporary or permanent impotence or sexual dysfunction among the 3617 men.

In the placebo group, impotence resolved in two men only after the study drug was stopped. In the simvastatin group, impotence resolved in 14 men despite continued simvastatin treatment. The difference of 28 cases versus 37 was not significant-Fisher's exact test: $\mathrm{P}=0.32$, Cox proportional hazards model: relative risk $1.30(95 \%$ confidence interval 0.80 to 2.12$), \mathrm{P}=0.29$. From these findings, it is unlikely that simvastatin causes impotence or sexual dysfunction.

Terje R Pedersen Head

Cardiology Department, Medical Clinic, Aker Hospital, University of Oslo, N 0514 Oslo, Norway Ole Færgeman Professor

Department of Medicine and Cardiology, Århus Amtssygehus, University of Århus, Århus, Denmark

1 Jackson G. Simvastatin and impotence. BMJ 1997;315:31 2 Scandinavian Simvastatin Survival Study Group. Randomized trial of cholesterol lowering in 4444 patients with coronary heart disease: the Scandinavian simvastatin survival study (4S). Lancet 1994; 344:1383-9.

\section{General practitioners are victims too}

EDITOR-Having just completed a series of eight meetings with some 500 general practitioners from around the country, I cannot believe the huge disparity between the espoused values of those who do not work as general practitioners and the near desperation of many who do.

Number of men in the Scandinavian simvastatin survival study spontaneously reporting temporary or permanent impotence or sexual dysfunction (placebo 1803, simvastatin 1814)

\begin{tabular}{lccccc}
\multirow{2}{*}{$\begin{array}{l}\text { Onset time } \\
\text { (after randomisation) }\end{array}$} & \multicolumn{2}{c}{ Placebo } & \multicolumn{2}{c}{ Simvastatin } \\
\cline { 2 - 3 } \cline { 5 - 6 } \cline { 5 - 6 } Impotence & 3 & Resolved & & Impotence & Resolved \\
\hline $2-3$ month & 2 & 0 & & 0 & 0 \\
\hline $4-12$ months & 2 & 3 & 5 & 4 \\
\hline Year 2 & 9 & 1 & 8 & 6 \\
\hline Year 3 & 4 & 1 & 4 & 1 \\
\hline Year 4 & 1 & 8 & 37 & 1 \\
\hline Year 5-6 & 7 & & 23 & 14 \\
\hline Total & 28 & 20 & &
\end{tabular}


Neuberger talks about patients not being consulted over the services offered. ${ }^{1}$ No one ever consulted most general practitioners about the 1990 contract or primary care groups-these issues are decided at the highest levels. In the mid-1980s many of us could start reducing our list sizes and giving more time for consultations. Home visits were not a chore, and care could be more personal and continuing. I don't care what the pundits say: the caring general practitioners who are still out there talk all the time about wanting to give more time to people and are frustrated at a professional level by their inability to offer the standard of care of which they know they are capable.

Most of what has occurred in my lifetime as a general practitioner has shown a complete lack of strategic coherence at the highest levels. The fact that we now apparently need 7000 doctors and 15000 nurses serves only to underline this.

Part of the solution is to increase users' feelings of control, but when people hear of spending sprees their first reaction is not to decrease their demand for services; however many bad doctors there might be, doctors in general are still fearsomely outnumbered by the great British public. People will vote with their feet, and that applies as much to doctors as it does to their patients; many doctors are just as confused by the changes as those they try to look after.

It is also oversimplistic to state that doctors know where to go when they are ill. Evidence from the Doctors Support Network shows that many (usually mentally ill) doctors are hopeless at knowing what to do when they are ill. They go to the same fallible specialists as their patients and end up, somewhat ironically, getting an abysmal service, excluded by the same old fashioned medical hierarchy and NHS structure that so damaged them in the first place. In truth, many general practitioners are as much victims as their patients are.

Chris Manning Secretary, Doctors Support Network Teddington, Middlesex TW11 9HG 100044.411@compuserve.com

Neuberger J. Primary care: core values. Patients' priorities. BMJ 1998;317:260-2. (25 July.)

\section{Public should be told that vaccines may have long term adverse effects}

EDIToR-Jefferson's editorial about vaccination and its adverse effects mentions our research. ${ }^{1}$ We found that immunisation starting at birth was associated with a decreased risk of insulin dependent diabetes, while immunisation starting after age 2 months was associated with an increased risk of diabetes in both rodents and humans. ${ }^{2}$ We initiated a collaboration with Dr Jaakko Tuomilehto to study the effect of Haemophilus influenzae type $\mathrm{b}$ vaccine on the incidence of diabetes. Roughly 116000 Finnish children were randomised to receive either four doses of the vaccine, starting at 3 months of age, or one dose at 24 months of age. ${ }^{3}$ We calculated the incidence of insulin dependent diabetes in both groups until age 10 and in a group that did not receive the vaccine- a cohort that included all 128500 children born in Finland in the 24 months before the study of the vaccine began.

A conference was held in Bethesda, Maryland, in May 1998 to discuss our data At the conference we stated that the data on the vaccine support our published findings that immunisation starting after the age of 2 months is associated with an increased risk of diabetes. Our analysis is further supported by a similar rise in diabetes after immunisation with $H$ influenzae type $\mathrm{b}$ vaccine in the United States ${ }^{4}$ and United Kingdom. ${ }^{5}$ Furthermore, the increased risk of diabetes in the vaccinated group exceeds the expected decreased risk of complications of $H$ influenzae meningitis.

Research into immunisation has been based on the theory that the benefits of immunisation far outweigh the risks from delayed adverse events and so long term safety studies do not need to be performed. When looking at diabetes-only one potential chronic adverse event-we found that the rise in the prevalence of diabetes may more than offset the expected decline in long term complications of $H$ influenzae meningitis. Thus diabetes induced by vaccine should not be considered a rare potential adverse event. The incidence of many other chronic immunological diseases, including asthma, allergies, and immune mediated cancers, has risen rapidly and may also be linked to immunisation.

We believe that the public should be fully informed that vaccines, though effective in preventing infections, may have long term adverse effects. An educated public will probably increasingly demand proper safety studies before widespread immunisation. We believe that the outcome of this decision will be the development of safer vaccine technology.

John Barthelow Classen* President

Classen Immunotherapies, 6517 Montrose Avenue, Baltimore, MD 21212, USA

Classen@vaccines.net

David C Classen* Infectious disease physician Division of Infectious Diseases, LDS Hospital, Salt Lake City, UT, USA

*The methods used in this research are covered by patents owned by Classen Immunotherapies. John Classen holds shares in Classen Immunotherapies; David Classen owns no shares in the company, receives no funding from it, and has no financial ties to it or to this research.

1 Jefferson T. Vaccination and its adverse effects: real or perceived. $B M J$ 1998:317:159-60. (18 July)

2 Classen DC Classen JB The timing of pediatric 2 Classen DC, Classen JB. The timing of pediatric mellitus. Infect Dis Clin Pract 1997;6:449-54.

mellitus. Infect Dis Clin Pract 1997;6:449-54.
Eskola J, Kayhty H, Takala AK, Peltola H, Ronnberg PR, Kela E, et al. A randomized, prospective field trial of a conjugated vaccine in the protection of infants and young children against invasive Haemophilus influenzae type disease. N Engl J Med 1990;323:1381-7.

4 Dokheel TM. An epidemic of childhood diabetes in the United States. Diabetes Care 1993;16:1606-11.

5 Gardner S, Bingley PJ, Sawtell PA, Weeks S, Gale EA. Rising incidence of insulin dependent diabetes in children under 5 years in Oxford region: time trend analysis. $B M J$ 1997:315:713-6

\section{Selective evidence was used to support link between immunisation and asthma}

EDIToR-Blomfield says that there is accumulating evidence that immunisation causes asthma. ${ }^{1}$ But he presents only evidence supporting the hypothesis when there is also evidence against it.

He quotes a retrospective cohort study that suggested a link between pertussis immunisation and asthma but not the subsequent randomised controlled trial that found no association. ${ }^{2}$ The findings of the New Zealand cohort study were based on only 23 children who did not receive triple (diphtheria, pertussis, and tetanus) vaccine or polio vaccine, for six of whom data were incomplete. ${ }^{3}$ If even one of these children developed asthma, the association with immunisation would not be significant. The cohort study has other important limitations. ${ }^{4}$ Furthermore, a British cohort study found no association between immunisation and wheeze but did find a lower risk of eczema among immunised children. ${ }^{5}$

Further research is clearly needed in this area. It is misleading to present only the evidence supporting the hypothesis when there is at least as much opposing it.

Osman David Mansoor Public health physician Ministry of Health, PO Box 5013, Wellington, New Zealand

1 Blomfield R. Childhood vaccination should have been included in asthma study. BMJ 1998; 317:205. (18 July.)

2 Nilsson L, Storsaeter J. Lack of association between pertu sis vaccination and symptoms of asthma and allergy. JAMA 1996; 275: 760 .

3 Kemp T, Pearce N, Fitzharris P, Crane J, Fergusson D, St George I, et al. Is infant immunization a risk factor for childhood asthma or allergy? Epidemiology 1997;8:678-80 McIntyre PB, O'Brien ED, Heath TC. Immunisation and asthma. Communicable Diseases Intelligence 1988;22:38.

5 Butler NR Golding J, eds. From birth to five: a study of the Butler NR, Golding J, eds. From birth to five: a study of the health and behaviour of Britain's 5-year-olds. Oxford:
Pergammon Press, 1986 .

\section{Sensitivity and specificity and their confidence intervals cannot exceed $100 \%$}

EDITOR-Stell and Gransden investigated the diagnostic accuracy of liquid media and direct culture of aspirated fluid as tests of septic bursitis. ${ }^{1}$ They reported that culture in liquid media had a sensitivity of $100 \%(95 \%$ confidence interval $92 \%$ to $108 \%$ ) and a specificity of $89 \%$ ( $74 \%$ to $104 \%)$.

As sensitivity and specificity cannot exceed $100 \%$, neither should their confidence intervals. Such impossible results arise when the standard large sample method for calculating confidence intervals for proportions is used when the proportion is near to zero or one or when the sample is small, or both. Even the use of a continuity correction, such as the subtraction of 0.5 from the numerator (as seems to have been used in the calculation of the above confidence interval for sensitivity) does not get around this problem. For the large sample method to be valid both the number of tests giving a negative result and the number giving a positive result 
should exceed 5. ${ }^{2}$ The values here are 17 and 0 for sensitivity, and 17 and 2 for specificity. Because the numbers are small, exact confidence intervals based on binomial probabilities should be calculated. These require computer programs or tables and give 95\% confidence intervals of $80 \%$ to $100 \%$ for sensitivity and $67 \%$ to $99 \%$ for specificity.

We are concerned that even these values are too high. Unbiased evaluation of the accuracy of a diagnostic test requires that the test results are compared with those of a good independent reference standard. ${ }^{4}$ Where such a standard does not exist, studies of diagnostic accuracy are problematic and can be misleading. Stell and Gransden used the definitive diagnoses made by an independent panel as their reference standard. The panel based its diagnoses on "all clinical, laboratory, treatment, and follow up data to the point of final discharge"; although ambiguous, this suggests that the results of the culture methods were in fact part of the data used to make the reference diagnosis. In this situation it is not surprising that high agreement is observed between the test and the reference standard. This bias is known as "incorporation bias" ${ }^{15}$ and nearly always leads to overestimation of the predictive abilities of the test. If the culture results were available to the independent panel the results of this study are likely to be overoptimistic.

Jonathan J Deeks Medical statistician

Douglas G Altman Director

ICRF/NHS Centre for Statistics in Medicine, Institute of Health Sciences, Oxford OX3 7LF J.Deeks@icrf.icnet.uk

1 Stell IM, Gransden WR. Simple tests for septic bursitis comparative study. BMJ 1998;316:1877-8. (20 June.)

2 Bland M. An introduction to medical statistics. 2nd ed Oxford: Oxford University Press, 1995:125-6.

3 Lentner C, ed. Geigy scientific tables. 8th ed. Basle: Geigy, 1982: 89-102

4 Jaeschke R, Guyatt GH, Sackett DL for the Evidence-Based Medicine Working Group. Users' guides to the medical literature. III How to use an article about a diagnostic test A: Are the results of the study valid? JAMA 1994:271:703-7.

Are the results of the study valid? JAMA 1994;271:703-7.

Ransohoff DF, Feinstein AR. Problems of spectrum and
bias in evaling the efficacy of diagnostic tests. $N$ Engl J Med 1978;299:926-30.

\section{Prospects for general practice research are bright despite research assessment exercise}

EDIToR-Medical academic staff have protested that the Higher Education Funding Councils' research assessment exercise is unjust, emphasises research at the expense of teaching, and is damaging medical schools. ${ }^{12}$ The effects on particular disciplines, however, are not apparent in publications from the councils, which relate to units of assessment and institutions rather than individual departments.

To assess the effects of 1996's research assessment exercise on university departments of general practice we surveyed all 27 heads of department in the United Kingdom at the end of 1997, asking about funding changes after the exercise and about teaching workload; we also suggested changes for the next exercise. Altogether 26 departments responded (24 undergraduate and two postgraduate only). Twenty heads reported
Relation between ratings received by units of assessment of academic departments of general practice and subsequent changes in departmental funding

\begin{tabular}{lccc}
\multirow{2}{*}{$\begin{array}{l}\text { Rating } \\
\text { received }\end{array}$} & \multicolumn{3}{c}{ Subsequent changes in departmental funding } \\
\cline { 2 - 4 } & Decrease & No change & Increase \\
\hline $2,3 \mathrm{~b}$ & 6 & 5 & 0 \\
\hline $3 \mathrm{a}, 4$ & 4 & 4 & 1 \\
\hline $5,5^{\star}$ & 0 & 1 & 2 \\
\hline
\end{tabular}

Kendall's $\sigma b=0.389, P=0.038$.

that funding had been reviewed in the light of the exercise, and five that a review was planned. Only three declared increased funding (including new posts funded by the councils in two departments); 10 reported reductions, which had led to redundancies in one department, disestablished or frozen posts in eight, and the use of alternative funds to keep staff in seven. The table shows the significant positive relation found between ratings and reported changes in funding.

Seventeen undergraduate departments were teaching in five years of the curriculum and seven in three years, and 18 heads expected their teaching load to increase. We found no relation, however, between research assessment exercise ratings and these measures, which suggests that increased teaching has not impaired research activity.

In response to suggested changes to the exercise, 20 heads agreed that health service research should be afforded greater status, 19 that the judging panel should include a social scientist, 11 that primary care should be a separate unit of assessment, and 10 that the total volume of output should count. Only seven agreed that journal impact factors should be used to judge papers, which tends to support the suggestion that panels should assign journal ratings in consultation with academics. ${ }^{2}$

Our findings suggest that the exercise's principle of selectively rewarding more highly rated departments is being followed in medical schools. This has proved costly to general practice (a fledgling academic discipline), at least in the short term, although we emphasise that the research assessment exercise in 1996 was conducted in the context of a downward trend in funding of research by the Higher Education Funding Councils. ${ }^{3}$ In future more funding may be channelled through the NHS research and development programme $^{4}$ and the Medical Research Council. ${ }^{5}$ The prospects for general practice research are therefore bright despite the 1996 research assessment exercise.

Tony Kendrick Professor of primary medical care University of Southampton, Aldermoor Health Centre, Southampton SO16 5ST

John Campbell Senior lecturer in general practice David Armstrong Reader in medical sociology Department of General Practice of Guy's, King's, and St Thomas's Medical School, London SE11 6SP

1 Beecham L. Medical academic staffs conference. $B M J$ 1998;316:1834-5

2 Williams G. Misleading, unscientific, and unjust: the United

Kingdom's research assessment exercise. BMJ 1998;316:

1079-82.
3 HEFCs set to lose $£ 100 \mathrm{~m}$ to research councils. Res Fortnight 1997;3:1.

4 NHS Executive. RED in primary care. National working group report. London: Department of Health, 1997

5 Medical Research Council. Primary health care. MRC topic review. London: MRC, 1997.

\section{Outcome of neonatal hypoglycaemia}

\section{Complete data are needed}

EDITOR-Ten years ago Lucas et al reported a retrospective multicentre study determining whether asymptomatic neonatal hypoglycaemia results in neurological damage. ${ }^{1}$ They found that moderate hypoglycaemia $(<2.6 \mathrm{mmol} / \mathrm{l})$ may have serious neurodevelopmental consequences if present on five or more different days during the first two months of life.

Subsequently, in October 1989, a Ciba Foundation discussion meeting was held in order to clarify the data and conclusions presented by Lucas et al. ${ }^{12}$ Sinclair and Steere, using specific criteria, recognised that all the published follow up studies were too flawed and inadequate to provide a definite conclusion. Lucas et al had assembled a large inception cohort in their study, with objective outcome criteria and with assessments done by people who were blind to category of exposure. Follow up was almost complete. However, they had not specified a criterion for hypoglycaemia, and sampling bias was not avoided. ${ }^{13}$ Lucas et al's study therefore did not provide strong evidence that neonatal hypoglycaemia impairs later development.

Despite this caveat the study by Lucas et al has received widespread attention and acceptance in both North America and Europe. Implications for the feeding and care of all neonates have been important; attempts have been made to maintain these comparatively high blood glucose concentrations as acceptable. ${ }^{4}$ In the United States these criteria have resulted in a fourfold increase in cases of medical litigation, and of awards (MC). Similar increases have occurred in England (A F Williams, personal communication).

Lucas et al have indicated to us that neurodevelopmental follow up of the 1988 cohort would clarify the importance of hypoglycaemia as stated in their preliminary report. ${ }^{1}$ The long term outcomes of all of their clinical trials of early nutrition on later health and development have been published. ${ }^{5}$ The original $B M J$ article ${ }^{1}$ is not mentioned, nor are any of the later follow up studies that compare glucose concentrations in the blood early in life and neurodevelopmental outcome. These data are available. We deserve to have the benefit of these observations, flawed as they may be.

Marvin Cornblath Lecturer in paediatrics Neonatology Division, Johns Hopkins Hospital, Baltimore, MD 21287, USA

Robert Schwartz Professor of pediatrics Brown University School of Medicine, Division of Pediatric Endocrinology and Metabolism, Providence, RI 02903, USA 
1 Lucas A, Morley R, Cole TJ. Adverse neurodevelopmental outcome of moderate neonatal hypoglycaemia. $B M J$ 1988;297:1304-8

2 Cornblath M, Schwartz R, Aynsley-Green A, Lloyd JK. Hypoglycaemia in infancy: the need for a rational definition. Pediatrics 1990;85:834-7.

3 Department of Clinical Epidemiology and Biostatistics, McMaster University Health Sciences Centre. How to read clinical journals. III: To learn the clinical course and prognosis of disease; IV: To determine etiology and causation. CMA Journal 1981;124:869-72; 985-90.

4 National Childbirth Trust. Hypoglycaemia of the breastfed newborn. Mod Midwife 1997 Oct 7:31-3.

5 Lucas A. Long term outcome trials of early nutrition on Lucas A. Long term outcome trials of early nutrition on later health and development. In: Perman JA, Rey J, eds. Lippincott-Raven, 1998:181-201.

\section{Authors' reply}

EDITOR-Our study design was not "flawed"-we had intended to explore the relation between glucose concentrations in blood in neonates and neurodevelopment at 18 months, based on over 6800 blood samplings in 661 preterm infants. We did not use a definition of hypoglycaemia as our purpose was to explore what concentrations might relate to adverse outcomes. The cut off we derived $(2.6 \mathrm{mmol} / \mathrm{l})$ was the same as the glucose concentration below which acute electrophysiological changes in the brain were observed elsewhere. ${ }^{1}$ It is at least biologically plausible that at such a sensitive stage in brain development, hypoglycaemia occurring on three to five days (a substantial time) could influence outcome.

We do, however, entirely accept the study's principal limitation-the difficulty of proving causation when an observational approach is used, as emphasised clearly in our paper. The $B M J$ publishes many articles that show worrying or provoking associations-for example, observations on small size in early life and ischaemic heart disease in later life. ${ }^{2}$ Such observations generate hypotheses or legitimate clinical concerns that should stimulate future studies.

The article Cornblath and Schwartz refer to, in Clinical Trials in Infant Nutrition, does not mention our hypoglycaemia study since it was not a trial. We have, however, now related neonatal hypoglycaemia, as defined and modelled previously, to overall intelligence quotient, ${ }^{3}$ reading and arithmetic, ${ }^{4}$ and motor performance $^{5}$ at 7.5-8 years. We have found evidence of persisting associations between neonatal hypoglycaemia and lower test scores, clinically significant in two of the four outcomes (arithmetic and motor tests), with approximately $0.5 \mathrm{SD}$ reduction in scores (adjusted for respiratory support, birth weight and gestation) after the neonatal concentration of blood glucose was $<2.6 \mathrm{mmol} / 1$ on $>3$ days $(\mathrm{P}<0.005)$. Although these data share the earlier same limitation, it seems that a plausible concern remains.

Rather than express discomfort over possible medical and legal misuse of our 1988 observation, investigators might have done more definitive studies - a priority identified at the Ciba symposium cited by Cornblath and Schwartz. If better clinical studies are not done we must operate with existing data, despite misgivings about medical or legal misuse. In any case, Cornblath and Schwartz agreed with us that it would not seem prudent to let a preterm neonate sustain a blood glucose concentration $<2.6 \mathrm{mmol} / 1$ for several days.

Alan Lucas MRC clinical research professor Institute of Child Health, London WC1N 1EH

Ruth Morley Senior research fellow

Royal Children's Hospital, Melbourne, Australia

1 Koh THHG, Aynsley-Green A, Tarbit M, Eyre JA. Neural dysfunction during hypoglycaemia. Arch Dis Child 1998;63:1353-8.

2 Barker DJP, Osmond C, Golding J, Kuh D, Wadsworth MEJ. Growth in utero, blood pressure in childhood and adul Growth in utero, blood pressure in childhood and adult
life, and mortality from cardiovascular disease. $B M J$ ife, and morta

3 Wechsler D. Wechsler intelligence scale for children-revised. Windsor: NFER-Nelson, 1976

Elliott CD. British Ability Scales. Windsor: NFER-Nelson, 1983

5 Stott DH, Moyes FA, Henderson SE. Test of motor impairment. Guelph, Ontario: Brook Educational Publishing, 1972

\section{Quality of care before admission to intensive care}

\section{Deaths on the wards might be prevented}

EDITOR-The greatest number of deaths in the intensive care unit, and the highes percentage mortality, is in patients admitted to intensive care from hospital wards. McQuillan et al focus on the inadequate care patients received before admission to the intensive care unit. ${ }^{2}$ Similar concerns led us to examine deaths on our hospital wards. We hypothesised that some patients with illnesses that they may recover from do not receive optimal treatment and have a cardiac arrest and die on the wards or deteriorate to the point where intensive care admission and resuscitation is deemed futile and a "do not resuscitate" order is written.

There were 316 deaths on our hospital wards between 1 June and 30 November 1997. A do not resuscitate order was not made for 55 patients $(17 \%)$. Their average age was 66.1 (SD 14.7, range 21-90) years and they were in hospital a median of 8 (interquartile range 3-14) days before death. Although 17 (31\%) patients received cardiopulmonary resuscitation before death, resuscitation would not have been appropriate in many of the others.

A do not resuscitate order was in the notes of 261 patients $(83 \%)$. In 11 we could not ascertain the date of the order. The average age of the remaining 250 patients was 74.9 (11.6, 34-96) years and they were in hospital a median of 11 (interquartile range 4-25) days before death. The orders were recorded a median of 3 (interquartile range 1-7) days before death. In 43 (17\%) the order was made on the day of death and in 45 $(18 \%)$ it was made on the day before death.

Most patients who died on the wards were in hospital for several days before death. Many do not resuscitate orders were made shortly before death, suggesting that resuscitation was pointless at this time. However, earlier intervention, active management, and admission to intensive care may have been of benefit in some of these patients as well as in a proportion of those without do not resuscitate orders. Evidence suggests that most ward patients have physiological abnormalities before a cardiac arrest $^{3}$ and that failure to recognise critically ill patients or take appropriate action results in deaths that could have been prevented. ${ }^{45}$ The patients admitted from wards to the intensive care unit are likely to represent the tip of the iceberg of preventable deaths on the ward. We can do better for many patients admitted to intensive care from the wards. Others with potentially treatable conditions may be deteriorating on the wards beyond the point where admission to intensive care can be of benefit.

D R Goldhill Senior lecturer

L M Worthington Specialist registrar

A J Mulcahy Specialist registrar

M M Tarling Research nurse

Anaesthetics Unit, Royal London Hospital, London E1 IBB

D.Goldhill@mds.qmw.ac.uk

1 Goldhill DR, Sumner A. Outcome of intensive care patients in a group of British intensive care units. Crit Care Med 1998:26:1337-45.

2 McQuillan P, Pilkington S, Allan A, Taylor B, Short A, Morgan G, et al. Confidential inquiry into quality of care before admission to intensive care. BMJ 1998;316:1853-63. (20 June.)

3 Franklin C, Mathew J. Developing strategies to prevent in hospital cardiac arrest: Analysing responses of physicians and nurses in the hours before the event. Crit Care Med 1994;22:244-7

4 Dubois RW, Brook RH. Preventable deaths: who, how often and why? Ann Intern Med 1988;109:582-9.

5 Neale G. Risk management in the care of medical emergencies after referral to hospital. J $R$ Coll Physician Lond 1998;32:125-9.

\section{Strategies for suboptimal care need evaluation}

EDITOR-McQuillan et al say that a medical emergency team and improved medical training may be solutions to the suboptimal care of inpatients. ${ }^{1}$ It would have been helpful if the authors had presented the American Society of Anesthesiologists (ASA) physical status on their surgical patients. A recent paper showed that high ASA physical status and surgery performed after hours were risk factors associated with severe postoperative events which required intervention by a medical emergency team (34 cases, incidence of $0.21 \%)^{2}$ While six patients were admitted to intensive care, the other cases on the ward were treated or reviewed by the team. ${ }^{3}$ This suggests that early and appropriate management of patients on the ward by the medical emergency team may prevent admissions to intensive care, reduce the length of stay in the unit, and prevent further morbidity and mortality, but this hypothesis needs to be tested. Postoperative care teams ${ }^{3}$ and acute pain service teams ${ }^{4}$ can complement the medical emergency team's intervention but will require good coordination within a hospital system. Improved medical training in communication, consulting, reasoning, and decision making skills is needed in junior doctors if they are to identify and manage critically ill patients earlier.

Preventing patients from falling through the healthcare net requires a system-wide approach-one that perceives the at risk patient as being on a continuum of care from the prehospital and ward settings through to discharge from intensive care and that addresses the fact that these patients require time-critical attention. In 
New South Wales, Australia, the health authority has dealt with this aspect of the problem. It has established expert critical care committees in each of the health regions, which are charged with monitoring and correcting deficiencies in critical care within and between both district and larger teaching hospitals at any point in the continuum of care within the region. ${ }^{5}$

It is not enough to focus on patient care within each specialty area of medical practice, as critically ill patients do not respect arbitrary practice boundaries. Whatever strategy is used, it must be tested rigorously to show that it does improve patient outcome. Increased vigilance and improvements in the overall quality of patient care in the healthcare system are paramount if there is to be a reduction in "preventable" morbidity and mortality.

Anna Lee Research fellow, centre for kidney research Tony O'Connell Staff specialist, department of intensive care

The New Children's Hospital, Parramatta, NSW 2124, Australia

1 McQuillan P, Pilkington S, Allan A, Taylor B. Short A, Morgan $\mathrm{G}$, et al. Confidential inquiry into quality of care before admission to intensive care BMJ 1998;316:1853-8. (20 June.)

2 Lee A, Lum ME, O'Regan WJ, Hillman KM. Early postoperative emergencies requiring an intensive care team intervention. Anaesthesia 1998;53:529-35.

3 Goldhill DR. Introducing the postoperative care team. $B M$ 1997;314:389

Riley RH. An acute pain service and preventable deaths in hospitals. Med J Aust 1996;164:573.

5 O'Connell T, Ieraci S, Raper R, Lyle D, Hillman K, Burrell

T, et al. New South Wales metropolitan critical care plan.

(2)

\section{Research into meningococcal disease is too fragmented}

EDITOR-Continuing research into meningococcal disease has reached a crossroads. A meeting last year on this subject, hosted by the Royal College of Physicians of London and sponsored by the Meningitis Research Foundation, presented an overview of the many treatment modalities currently being explored in an attempt to reduce a still unacceptable morbidity and mortality. So diverse and sometimes contradictory were these modalities that there was a plea for the audience not to leave disheartened and confused, but this seemed inevitable owing to the diversity of policies tried piecemeal. Since it will probably take many years to develop appropriate vaccines, how can we create a research ethic in the United Kingdom that will allow us to answer the difficult management questions posed by this illness?

In the early 1970 s paediatric oncologists in the United Kingdom had reached a similar situation in the management of acute leukaemias. The basic foundations for treatment had been laid, but they had to be built on in a structured and defined way. This led to the Medical Research Council's acute lymphoblastic leukaemia trials, which were a triumph for paediatrics in the United Kingdom; management of a disease of which each centre had a small number of cases was explored with a step by step nationwide consensus of research, with a supervisory board of researchers coordinating and analysing the results.

Piecemeal research based on small numbers in poorly controlled ways may lead to intuitive experience, but major questions about management may never be adequately answered. Surely future research on meningococcal disease has reached the stage where the approach used in the United Kingdom acute lymphoblastic leukaemia trials offers the best chance of answering difficult management questions. Specialists can organise themselves into a powerful national body to instigate, coordinate, and then interpret well designed multicentre collaborative trials and build on the results with a logical programme of ongoing research.

I would plead that those specialising in meningococcal disease give their urgent attention to this matter, initially in setting up a database register for every child with meningococcal disease in the United Kingdom. A small coordinating body of such specialists could then plan a unified programme of multicentre research with defined aims in a stepwise logical progression. We should use the experience of our paediatric oncology colleagues and learn from them.

S Hoare Consultant paediatrician

Paediatric Infectious Diseases Unit, Newcastle General Hospital, Newcastle upon Tyne simon.hoare@dial.pipex.com

\section{Refugee doctors can do valuable work in European host countries}

EDITOR-In their editorial Berlin et al emphasised the importance of finding new approaches to integrate medical doctors living as refugees in European host countries. ${ }^{1}$ In a project developed during the war in neighbouring Yugoslavia, the Austrian Board of Psychotherapy set up a pilot training programme for doctors and psychologists from Bosnia-Hercegovina who had been forced to flee the country. Participants underwent two years of training in principles of supportive psychotherapy, to supplement their general medical and psychological expertise. The main problem was that the participants had no access to work in Austrian hospitals, which require a (usually unavailable) work permit and have a complicated procedure of postgraduate qualification. Over 100000 Bosnian speaking refugees put a heavy stress on medical and psychotherapeutic transcultural resources, and language, emergency counselling, and supportive skills were therefore urgently needed.

The interdisciplinary training programme included seminars, therapy by self experience, and supervision. All participants were able to use their skills in counselling, support, and mediation between Austrian healthcare providers and Bosnian refugees.

Participants were paid, whereas they had worked in menial jobs before. The accept- ance and dedication of the group's members made the project successful. One of the most important experiences was the first contact with a large number of seriously traumatised refugees, who had had no prior contact with counselling or medical and psychological treatment and were mainly survivors of war atrocities and concentration camps. Clients reported that they were relieved to be able to talk to care givers from their own group, who offered understanding and a common language. The costs of the programme were refunded by the Austrian interior ministry's integration department.

We can only support Berlin et al's argument. We need the language, culture, and professional skills of those who come as refugee doctors. Efforts should be made and special programmes set up in host countries to help integrate foreign doctors to promote an active community outreach in health care.

Thomas Wenzel Secretary

WPA Section on Psychological Aspects of

Persecution and Torture, University Hospital for

Psychiatry, A-1090 Vienna, Austria

1 Berlin A, Gill P, Eversley J. Refugee doctors in Britain: a wasted resource. $B M J$ 1997;315:264.

\section{Iraqi doctors regret bombing by United States and Britain}

EDIToR-On behalf of all British Iraqi doctors and Iraqi doctors living in Iraq the Iraqi Medical Association wishes to express its concern about the recent bombing of Iraq by the United States and Britain. The people of Iraq are already suffering as a result of shortages of food, medicine, and basic medical facilities, which have a direct impact on morbidity and mortality.

The bombing campaign will inevitably lead to further deterioration in the humanitarian situation. The terrifying public health hazards of the bombing-apart from its direct destructive effect on people and the tremendous thundering and ripping sounds of explosions-have devastating effects (both short term and long term) on people, particularly the very young and very old. Even more unfortunately, the campaign occurred at the start of the holy periods of Ramadan and Christmas.

The medical profession is a humanitarian profession, and all healthcare workers do their best, including Iraqi doctors inside and outside the United Kingdom. They do their best to ensure people's wellbeing regardless of their religion, race, and political affiliation. What is really sad and extremely frustrating is to see large numbers of innocent people suffering for reasons that are easily avoidable.

Khalid Alshafi President

Iraqi Medical Association, PO Box 23701, London W5 0 TU

For the executive committee of the association.

Rapid responses
$\begin{aligned} & \text { Rapid responses submitted directly to our } \\ & \text { website are available on www.bmj.com }\end{aligned}$

